\title{
ANTIMICROBIAL SURFACES OBTAINED FROM BLENDS OF BLOCK COPOLYMERS SYNTHESIZED BY SIMULTANEOUS ATRP AND CLICK CHEMISTRY REACTIONS
}

\author{
Marta Alvarez-Paino, ${ }^{1}$ Pablo Bonilla, ${ }^{2}$ Rocío Cuervo-Rodríguez, ${ }^{2}$ Fátima López-Fabal, ${ }^{3}$ \\ José L. Gómez-Garcés, ${ }^{3}$ Alexandra Muñoz-Bonilla, ${ }^{1^{*}}$ Marta Fernández-García ${ }^{1 *}$ \\ ${ }^{1}$ Instituto de Ciencia y Tecnología de Polímeros (ICTP-CSIC), C/Juan de la Cierva 3, \\ 28006 Madrid, Spain
}

${ }^{2}$ Facultad de Ciencias Químicas, Universidad Complutense de Madrid, Avenida Complutense s/n, Ciudad Universitaria, 28040 Madrid, Spain

${ }^{3}$ Hospital Universitario de Móstoles, C/Río Júcar, s/n, 28935 Móstoles, Madrid, Spain

\section{ABSTRACT}

A series of amphiphilic block copolymers based on styrene (S) and a monomer bearing both thiazole and triazole groups (MTA) were synthesized by combination of ATRP and click chemistry. In particular, two approaches were followed; the direct ATRP from a PS macroinitiator of the pre-synthesized MTA antimicrobial monomer; and the simultaneous synthesis and polymerization of the MTA through a one-step 'click chemistry'/ATRP process. Both strategies conduct to well-defined block copolymers with controlled molecular weight and low polydispersity. Subsequent quaternization of the thiazole and triazole groups of MTA units with butyl iodine renders systems with antimicrobial properties. Although these systems presented relatively low antimicrobial activity against bacteria and fungi in aqueous media, the preparation of surfaces functionalized with these copolymers leads to potent antimicrobial surfaces, especially against gram-positive bacteria.

Keywords: Block copolymers, ATRP, click chemistry, antimicrobial, surfaces. 


\section{INTRODUCTION}

Antimicrobial polymers have been postulated as a good alternative to solve the antimicrobial resistance, which causes severe illnesses and deaths [1-3]. This is thanks to their properties such as chemical stability, and their difficulty to permeate through the skin of humans or animals [4]. But more important is the mechanism of action, which differs from the antibiotics and therefore, the antimicrobial polymers suffer less risk of microbial resistance. There are a wide variety of antimicrobial polymeric systems $[5,6]$ and one of the most studied are polycations [6, 7], in particular those with quaternary nitrogen atoms. These structures interact electrostatically with the negative charged bacteria cell wall, causing disruption of the wall and the posterior death.

There are many strategies to design synthetic antimicrobial polymers. It is desirable to control the chain length, composition and topology of the polymer to optimize its activity. In recent years, advances in synthetic chemistry have allowed the preparation of welldefined and multi-functional antimicrobial polymers in a relatively facile manner, which would help in systematic investigations to stablish a relation between structure and antimicrobial activity. Moreover, during the last decades there have been widespread explored controlled/living polymerization methodologies [8]; especially controlled radical polymerization (CRP) techniques [9, 10] are of great importance to obtain well-defined charged copolymers such as cationic antimicrobial polymers. Techniques such as atom transfer radical polymerization (ATRP) $[11,12]$, nitroxide-mediated polymerization (NMP) $[13,14]$, reversible addition fragmentation chain transfer (RAFT) $[15,16]$ are typically employed to obtained polycations by either direct polymerization of cationic monomers or by introduction of the cationic groups by post-polymerization reactions.

Furthermore, vinyl-triazole monomers and hence their polymeric derivatives, have shown great potential in different areas as biomaterials, ion exchange membranes, drug delivery or catalytic systems and poly(ionic liquid)s, among others [17-19]. Those are mainly achieved by azide-alkyne click chemistry, which renders high yields and feasibility [20]. In previous works, our group has tested the effectiveness in aqueous solution of different quaternized homopolymers and copolymers bearing two cationic groups per monomer units, thiazole and triazole moieties. These polymers were synthesized by both conventional radical polymerization and by controlled techniques via simultaneous ATRP and click chemistry [12, 21-23]. In addition, the block copolymers bearing these cationic structures were employed as surfactant in emulsion polymerization of butyl methacrylate and subsequently antimicrobial coating were also prepared from the resulting latex [20]. It was showed, as previously demonstrated in other publications [21, 22], that the use of these block copolymers as surfactants in low percentage allows the decoration of surfaces with antimicrobial structures. The resulting coatings presented antimicrobial efficiency 
against Staphylococcus aureus and $S$. epidermidis bacteria, both gram-positive bacteria. The covering of surfaces with antimicrobial films is becoming an interesting alternative to minimize the transmission of infections, especially in nosocomial infections. In addition, antimicrobial films could prevent the biofilm formation, which is one of the major problems in microbial infections. Much effort has done in preparing antifouling or bacteriostatic surfaces, which inhibit the microbial growth by repelling microbes. However, sometimes the microbial adherence on specific surface is unavoidable, so microorganisms can survive and proliferate. Once the biofilm is formed; its elimination is highly costly and is responsible of morbidity and mortality in many hospitalized patients, particularly implicated in persistent infections of medical implants. To this concern, antimicrobial polymeric surfaces with bactericidal performance able to kill microbes, >99.9\% [8], are an increasing alternative to prevent the spread of microbial infections and formation of biofilm [9].

The aim of the current study is the synthesis of antimicrobial polymers containing quaternary nitrogen moieties for the preparation of antimicrobial surfaces. Several block copolymers based on polystyrene and 1-(2-(4-methylthiazol-5-yl)ethyl)-1H-1,2,3-triazol-4yl)methyl methacrylate (MTA) were synthesized and their antimicrobial activity was analyzed as well. Secondly, antimicrobial films were prepared from these copolymers by simply polymer blending approach with a commercial high molecular weight polystyrene, which was employed as major component. This method involves the preparation of active surfaces by the physical incorporation of the antimicrobial agent in relatively low concentration into a polymer matrix. In contrast to other approaches consisting in the covalent attachment of the antimicrobial agent onto the surface [23, 24], this approach is an easy and straightforward method that avoids multiple chemical and modification steps which are generally needed in other strategies. Another advantage of the blending approach is that the surface composition can be controlled by surface segregation. The surface segregation implies the preferential migration of one blend component to the interface, i.e. antimicrobial agent. This process can be spontaneous or in contrast needs additional treatments such as annealing procedures. Regardless of this, the surface could be repeatedly and continuously enriched in the active component by means of this surface segregation process. In this work, the effectiveness of these resulting surfaces was analyzed against both gram-positive and gram-negative bacteria and fungi and as a function of the amount of block copolymer added into the polystyrene matrix.

\section{EXPERIMENTAL PART}

\section{Materials}

The following reactants were used without previous purification: ethyl a-bromoisobutyrate (EBriB; 98\%; Sigma-Aldrich); copper (I) bromide (CuBr; 99.9\%; Sigma-Aldrich); copper (I) 
chloride $(\mathrm{CuCl}, \quad 97 \%$, Sigma-Aldrich); $\quad N, N, N, N$,',N'"-pentamethyldiethylenetriamine (PMDETA; 99\%; Sigma-Aldrich); 2-(4-methylthiazol-5-yl)ethanol ( $\geq 98 \%$; Sigma-Aldrich); methanesulfonyl chloride ( $\mathrm{MsCl}$; $\geq 99.7 \%$; Sigma-Aldrich); sodium azide $\left(\mathrm{NaN}_{3} ;<99 \%\right.$; Sigma-Aldrich); chloroform ( $\geq 99 \%$; Scharlau); tetrahydrofuran (THF; 99.5\%; Carlo Erba); methanol (99.5\%; Panreac); ethyl acetate (99.5\%; Panreac); hexane (99\%; Scharlau); propargyl methacrylate (98\%; Alfa Aesar); tert-butanol (t-BuOH; 99,5\%; Acros Organics); copper sulfate (CuSO $4 ; \geq 99 \%$; Sigma-Aldrich); sodium ascorbate ( $\geq 98 \%$; Sigma-Aldrich); 1-iodobutane (99\%; Sigma-Aldrich); aluminum oxide (neutral and basic; Sigma-Aldrich); anhydrous N,N-dimethylformamide (DMF; 99.8\% Alfa Aesar); anhydrous dichloromethane (DCM; $\geq 99.8 \%$; Sigma-Aldrich); cellulose dialysis membrane (CelluSep T1; Membrane Filtration Products, Inc.) and high-molecular-weight polystyrene $\left(\mathrm{PS}_{1950}, \mathrm{M}_{\mathrm{w}}=2.03 \times 10^{5}\right.$ $\mathrm{g} / \mathrm{mol}$; Basf) used as the polymeric matrix. Round glass coverslips of $12 \mathrm{~mm}$ in diameter were supplied from Ted Pella, Inc.

Styrene monomer (S; $\geq 99 \%$; Sigma-Aldrich) was purified by column chromatography (basic alumina). Triethylamine $\left(\mathrm{Et}_{3} \mathrm{~N} ; \geq 99 \%\right.$; Aldrich) was dried by distillation over potassium hydroxide before use while 1-(2-(4-methylthiazol-5-yl)ethyl)-1H-1,2,3-triazol-4yl)methyl methacrylate (MTA) monomer was synthesized following the procedure described in the literature [22].

The following reactants were used in microbiological assay: sodium chloride solution ( $\mathrm{NaCl}$ suitable for cell culture; BioXtra; Aldrich); phosphate buffered saline powder (PBS, $\mathrm{pH} 7.4$; Aldrich); Triton $\mathrm{X}-114$ solution (for molecular biology, $\sim 10 \%$ in $\mathrm{H}_{2} \mathrm{O}$, BioUltra; Aldrich). In vitro antimicrobial experiments were performed in 96-well microplates (BD Biosciences) with the aid of a Finnpipette ${ }^{\mathrm{TM}} \mathrm{F} 2$ (Thermo Scientific) as a multichannel pipette and appropriately sized sterile pipette tips. BBL ${ }^{\mathrm{TM}}$ Mueller-Hinton broth was purchased from Becton, Dickinson and Company and was used as a microbial growth medium. American Type Culture Collection (ATCC): Pseudomonas aeruginosa ( $P$. aeruginosa, ATCC 27853), Staphylococcus aureus (S. aureus, ATCC 29213), were used as bacterial strains, and the yeast Candida parapsilosis (C. parapsilosis, ATCC 22109) was used as fungal strain and purchased from Oxoid.

\section{Characterization}

${ }^{1} \mathrm{H}$ and ${ }^{13} \mathrm{C}$ Nuclear Magnetic Resonance (NMR) measurements were carried out at room temperature with a Bruker DPX spectrometer (300 MHz for ${ }^{1} \mathrm{H}$ and $75 \mathrm{MHz}$ for ${ }^{13} \mathrm{C}$ ) using deuterated solvents $\left(D M S O-\mathrm{d}_{6}\right.$ and $\mathrm{CDCl}_{3}$ ) purchased from Sigma-Aldrich. Coupling constants $(\mathrm{J})$ are expressed in $\mathrm{Hz}$ and chemical shifts $(\delta)$ in ppm using solvent residual peak as references $\left({ }^{1} \mathrm{H}: 7.27 \mathrm{ppm},{ }^{13} \mathrm{C}: 77.26\right.$ ppm; $\left.\mathrm{CDCl}_{3}\right),\left({ }^{1} \mathrm{H}: 2.62 \mathrm{ppm} ;{ }^{13} \mathrm{C}: 39.52\right.$ ppm; DMSO- $\left.d_{6}\right)$. Peak multiplicity is represented in the following way: singlet (s), doublet 
(d), triplet (t), multiplet $(\mathrm{m})$, doublet of doublets (dd), triplet of doublets (td), broad multiplet $(\mathrm{bm})$. The delayed time variation (10 s) does not imply a significant change in the signals. The Fourier Transform Infrared (FTIR) spectra of $\mathrm{KBr}$ pellets were recorded using a Perkin Elmer Spectrum One.

Molecular weights and polydispersity indexes of polystyrene and block copolymers were determined by gel permeation chromatography (GPC) on Waters Division Millipore system composed by a manual injector, a 515 HPLC Pump Waters and a Waters 2414 refractive index detector. The system included four Styragel columns in series (HR2, HR3 and HR4, Waters Division Millipore). $1 \mathrm{~mL} / \mathrm{min}$ flow rate of THF (GPC grade stabilized with $250 \mathrm{ppm}$ BHT; Scharlau) as eluent and $35 \stackrel{\circ}{C}$ were used for polystyrene characterization. The calibration was made with polystyrene standards (Polymer Laboratories LTD). The samples were filtered previous injection with $0.2 \mu \mathrm{m}$ OEM Syringe Filter PTFE. Alternatively, $1 \mathrm{~mL} / \mathrm{min}$ flow rate of DMF (GPC grade stabilized with $0.1 \mathrm{M} \mathrm{LiBr}$; Scharlau) as eluent and $50{ }^{\circ} \mathrm{C}$ were used for copolymers determination. The calibration was made with poly (methyl methacrylate) standards (Polymer Laboratories LTD).

Materials for biological experiments were already sterile or were sterilized in an autoclave before use. The optical density of the microorganism suspensions was measured in McFarland units by a DensiCHEKTM Plus (VITEK, bioMérieux) and incubations were performed at $37^{\circ} \mathrm{C}$ in a Jouan IQ050 incubator.

SEM micrographs of the films after incubation with bacteria during $24 \mathrm{~h}$ ( $S$. aureus

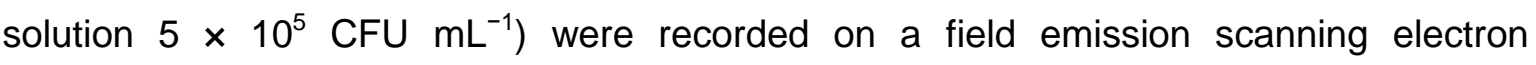
microscope (FE-SEM) Hitachi SU 8000 at $30 \mathrm{kV}$. Prior the visualization of the films, the surfaces were carefully rinsed several times with PBS, and the bacteria were fixed with $10 \%$ formalin solution for 60 minutes at room temperature. Subsequently, the films were washed twice with PBS and water, and finally dried for $10 \mathrm{~min}$ with ethanol/water mixtures increasing sequentially the ethanol content from 30 to 50,70 and $100 \%$.

\section{Synthesis of polystyrene macroinitiator}

In a typical experiment via atom transfer radical polymerization (ATRP), $0.4585 \mathrm{~g}$ (3.20 $\mathrm{mmol})$ of $\mathrm{CuBr}$ and $20.002 \mathrm{~g}(192.0 \mathrm{mmol})$ of styrene were placed in a round bottom flask. The solution was deoxygenated by purging with argon. Then, PMDETA (0.68 mL; 3.26 $\mathrm{mmol}$ ) was added and the reaction mixture was immersed into a silicone bath at $85{ }^{\circ} \mathrm{C}$. Subsequently, $0.48 \mathrm{~mL}$ ( $3.27 \mathrm{mmol}$ ) of EBriB was added under argon atmosphere. After 4 hours, the mixture was dissolved in THF and passed through a neutral alumina column to remove the copper catalyst. The polymer was isolated by precipitation in methanol, filtered and dried under vacuum. Then, $13.08 \mathrm{~g}$ (65\%) of a white solid were obtained. The number 
average molecular weight was estimated from GPC measurement in THF, $M_{n}{ }^{\text {THF }}=5660$ $\mathrm{g} / \mathrm{mol}$; degree of polymerization, $D P_{n}=54$ and polydispersity index, $M_{w} / M_{n}=1.21$. The copolymer was also analyzed by GPC in DMF, $M_{n}{ }^{D M F}=1800 \mathrm{~g} / \mathrm{mol}, \mathrm{M}_{\mathrm{w}} / \mathrm{M}_{\mathrm{n}}{ }^{\mathrm{DMF}}=1.11$.

\section{Synthesis of 2-(4-methylthiazol-5-yl)ethanol methanesulfonate (1)}<smiles>Cc1ncsc1CCO</smiles><smiles>CS(=O)(=O)Cl</smiles>
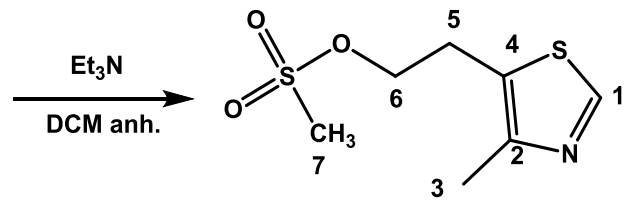

(1)

In a round flask under argon flow, $25.013 \mathrm{~g}$ (175 mmol) of 2-(4-methylthiazol-5-yl)ethanol were placed. Subsequently, $80 \mathrm{~mL}(124 \mathrm{mmol})$ of anhydrous dichloromethane (DCM) and $26 \mathrm{~mL}$ (187 mmol) of triethylamine were carefully added through a dropping funnel. The solution was introduced into an ice bath at $0{ }^{\circ} \mathrm{C}$ during drop by drop addition (30 minutes) of $14.5 \mathrm{~mL}(187 \mathrm{mmol})$ of methanesulfonyl chloride. After 4 hours at room temperature under argon atmosphere, $75 \mathrm{~mL}$ of $\mathrm{NaHCO}_{3}$ were added and the solution was extracted with $2 \times 30 \mathrm{~mL}$ of $\mathrm{DCM}$. The organic phase was dried with $\mathrm{MgSO}_{4}$, filtrated and evaporated to give the compound (1) $(37.49 \mathrm{~g}, 97 \%)$ as a brown oil. ${ }^{1} \mathrm{H}-\mathrm{NMR}\left(300 \mathrm{MHz} \mathrm{CDCl}_{3}\right), \delta$ (ppm): 8.63 (s, 1H, H-1), 4.36 (t, 3H, J=6.3, H-6), 3.23 (t, 2H, J=6.4, H-5), 2.97 (s, 3H, H7), 2.42 (s, 3H, H-3); ${ }^{13} \mathrm{C}-\mathrm{NMR}$ (75 MHz CDCl 3 ), $\delta$ (ppm): 150.3 (C-1), 150.0 (C-2), 125.3 (C-4), 69.5 (C-6), 37.4 (C-7), 26.3 (C-5), 14.9 (C-3) [22].

\section{Synthesis of 2-(4-methylthiazol-5-yl)ethanol azide (2)}

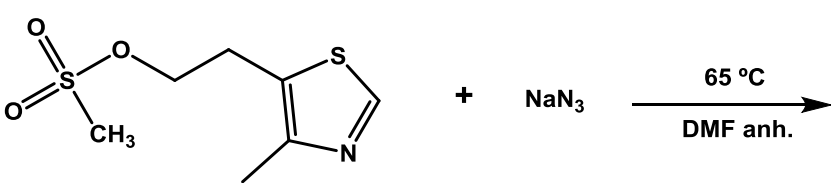

(1)

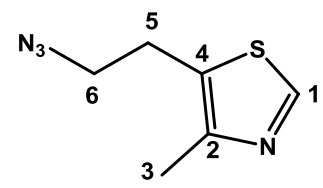

(2)

To a solution of $15.249 \mathrm{~g}$ (69 mmol) of 2-(4-methylthiazol-5-yl)ethanol methanesulfonate (1) in $250 \mathrm{~mL}$ of anhydrous DMF under argon flow, $12.415 \mathrm{~g}(191 \mathrm{mmol})$ of sodium azide were added. Then, the reaction mixture was introduced into an oil bath at $65{ }^{\circ} \mathrm{C}$ for $3 \mathrm{~h}$ under argon atmosphere. After the solvent was evaporated, the residue was washed several times with ethyl acetate. The combined organic solutions were extracted with $\mathrm{NaCl}$ saturated aqueous solution, dried on $\mathrm{MgSO}_{4}$, filtered and evaporated to give the crude product as a dark orange liquid. The product was purified by silica gel column chromatography using hexane/ethyl acetate 1:1 as eluent. Compound (2) was obtained as yellow oil (9.01, 78\%). ${ }^{1} \mathrm{H}-\mathrm{NMR}\left(300 \mathrm{MHz} \mathrm{CDCl}_{3}\right), \delta(\mathrm{ppm}): 8.52(\mathrm{~s}, 1 \mathrm{H}, \mathbf{H}-\mathbf{1}), 3.41$ (t, J = $6.8 \mathrm{~Hz}, 2 \mathrm{H}, \mathrm{H}-6), 2.94$ (t, J = 6.8 Hz, 2H, H-5), 2.33 (s, 3H, H-3); ${ }^{13} \mathrm{C}-\mathrm{NMR}(75 \mathrm{MHz}$ $\mathrm{CDCl}_{3}$ ), $\delta(\mathrm{ppm}): 155.2$ (C-1 and C-2), 132.4 (C-4), 57.2(C-6), 31.4 (C-5), 20.0 (C-3) [22]. 
Synthesis of (1-(2-(4-methylthiazol-5-yl)ethyl)-1H-1,2,3-triazol-4-yl)methyl methacrylate monomer (MTA)<smiles>C#CCOC(=O)C(=C)C</smiles>

(2)

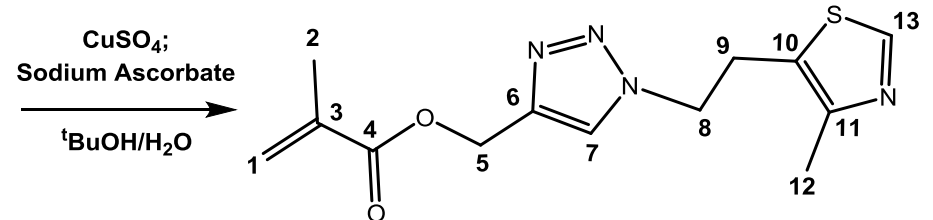

MTA

In a round-bottom flask were added $4.079 \mathrm{~g}(24.2 \mathrm{mmol})$ of azide (2), $3.002 \mathrm{~g}$ of propargyl methacrylate $(24.2 \mathrm{mmol}), 0.483 \mathrm{~g}(22.4 \mathrm{mmol})$ of sodium ascorbate, $0.187 \mathrm{~g}(1.17 \mathrm{mmol})$ of $\mathrm{CuSO}_{4}$ and $40 \mathrm{~mL}$ of $t-\mathrm{BuOH} / \mathrm{H}_{2} \mathrm{O}(1: 1)$. After stirring at room temperature for $18 \mathrm{~h}$, the solvent was evaporated to give the crude product, which was purified by column chromatography (silica gel, ethyl acetate). The compound MTA was obtained as a yellow liquid (6.46 g, 91\%). ${ }^{1} \mathrm{H}-\mathrm{NMR}\left(300 \mathrm{MHz} \mathrm{CDCl}_{3}\right), \delta(\mathrm{ppm}): 8.57(\mathrm{~s}, 1 \mathrm{H}, \mathbf{H}-13), 7.38(\mathrm{~s}, 1 \mathrm{H}$, $\mathbf{H - 7}$ ), 6.09 (s, 1H, H-1), 5.55 (s, 1H, H-1), 5.23(s, 2H, H-5), 4.53 (t, J = $6.8 \mathrm{~Hz}, 2 \mathrm{H}, \mathbf{H - 8}$ ), 3.37(t, J = 6.8 Hz, 2H, H-9), 2.17 (s, 3H, H-12), 1.90 (dd, J=1.2, $1.6 \mathrm{~Hz}, 3 \mathrm{H}, \mathbf{H - 2}$ ); ${ }^{13} \mathrm{C}-$ NMR (75 MHz $\mathrm{CDCl}_{3}$ ), $\delta$ (ppm): 167.2 (C-4), 150.8 (C-13), 150.2 (C-11), 143.0 (C-6), 135.8 (C-3), 126.3 (C-7), 125.8 (C-10), 124.4 (C-1), 57.7 (C-5), 51.1 (C-8), 27.4 (C-9), 18.3 (C-2), 14.5 (C-12) [22].

\section{Synthesis of block copolymers through simultaneous 'click chemistry'/ATRP (procedure A)}

Typical synthesis was as follows: the macroinitiator ( $\mathrm{PS}_{54}, 0.4476 \mathrm{~g} ; 0.0788 \mathrm{mmol}$ ) was dissolved in $5 \mathrm{~mL}$ of anhydrous DMF. Azide (2) (4.008 g; $24 \mathrm{mmol})$, propargyl methacrylate $(1.52 \mathrm{~mL}, 11.9 \mathrm{mmol})$, and PMDETA $(66.8 \mu \mathrm{L} ; 0.32 \mathrm{mmol})$ were then added into the solution. The mixture was deoxygenated by purging with argon and subsequently, copper (I) chloride, $0.0083 \mathrm{~g}(0.084 \mathrm{mmol})$, was added. The solution was maintained during 6.5 hours under argon atmosphere at $70 \stackrel{\circ}{ } \mathrm{C}$. The polymerization was stopped by exposition to air and cooling down, and the mixture passed over neutral alumina column eluting with chloroform. Afterwards, the solvent was eliminated and the reaction mixture was poured into isopropanol. The filtered block copolymer $\mathbf{P S}_{54}-\boldsymbol{b}-\mathbf{P M T A} \mathbf{A}_{36}$ was dried under vacuum and obtained as a yellowish solid (0.837 g). ${ }^{1} \mathrm{H}-\mathrm{NMR}\left(300 \mathrm{MHz} \mathrm{CDCl}_{3}\right), \delta$ (ppm): 8.57 (s, 1H, CH thiazole), $7.82\left(\mathrm{~m}, 1 \mathrm{H}, \mathrm{CH}\right.$ triazole), 7.00-6.43 (bm, 5H, $\left.\mathrm{H}_{\mathrm{Ar}} \mathrm{PS}\right)$, 5.05 (bs, 2H, OCH$)_{2}$, 4.62 (bs, 2H, $\mathrm{NCH}_{2}$ ), 3.36 (bs, 2H, $\mathrm{CH}_{2}$ ), 2.17 (s, 3H, $\mathrm{CH}_{3}$ thiazole), 2.00-1.00 (m, 5H, CH, $\mathrm{CH}_{2}$ main chain), 1.00-0.50 (m, 3H, $\mathrm{CH}_{3}$ PMTA). 
The general click chemistry/ATRP procedure described above was followed for the preparation of block copolymers varying the number of repeating MTA units of the hydrophilic blocks. PS $_{54}-b-$ PMTA $_{111}$, was prepared from the copolymerization of $6.758 \mathrm{~g}$ (40.2 mmol) of azide (2), $0.3796 \mathrm{~g}(0.067 \mathrm{mmol})$ of PS macroinitiator, $2.55 \mathrm{~mL}$ (20.1 $\mathrm{mmol})$ of propargyl methacrylate, $56.0 \mu \mathrm{L}(0.268 \mathrm{mmol})$ of PMDETA and $0.0066 \mathrm{~g}(0.067$ mmol) of $\mathrm{CuCl}$. The diblock copolymer $\mathbf{P S}_{54}-\boldsymbol{b}-\mathbf{P M T A}_{22}$ was prepared from $4.016 \mathrm{~g}$ (23.8 $\mathrm{mmol})$ of thiazole azide $(2), 0.898 \mathrm{~g}(0.158 \mathrm{mmol})$ of PS macroinitiator, $1.52 \mathrm{ml}(11.9$ $\mathrm{mmol})$ of propargyl methacrylate, $132.5 \mu \mathrm{L}(0.635 \mathrm{mmol})$ of PMDETA and $0.0157 \mathrm{~g}(0.158$ $\mathrm{mmol}$ ) of $\mathrm{CuCl}$. The block copolymers were obtained as yellowish solids: PS $_{54}-b-\mathrm{PMTA}_{111}$ $(1.87 \mathrm{~g})$ and $\mathrm{PS}_{54}-b-\mathrm{PMTA}_{22}(0.88 \mathrm{~g}) .{ }^{1} \mathrm{H}-\mathrm{NMR}$ spectra of these block copolymers show similar signals and shifts of those found in $\mathrm{PS}_{54}-b-\mathrm{PMTA}_{36}$.

\section{Synthesis of block copolymers via ATRP of MTA (procedure B)}

To a solution of polystyrene macroinitiator $(0.452 \mathrm{~g} ; 0.08 \mathrm{mmol})$ and $3.545 \mathrm{~g}(12 \mathrm{mmol})$ of MTA in $5 \mathrm{ml}$ of anhydrous DMF, were added $66.8 \mu \mathrm{L}(0.32 \mathrm{mmol})$ of PMDETA. The solution was deoxygenated by purging with argon for at least 25 minutes and then $0.008 \mathrm{~g}$ $(0.081 \mathrm{mmol})$ of $\mathrm{CuCl}$ were added. The reaction was stirred under argon atmosphere at $70^{\circ} \mathrm{C}$ during $6.5 \mathrm{~h}$. The polymerization was terminated by cooling and the mixture passed over neutral alumina column eluting with chloroform. The organic solution was concentrated and the block copolymer $\mathbf{P S}_{54}-\mathbf{b}-\mathbf{P M T A}_{37}$ was obtained as a yellowish solid $(0.67 \mathrm{~g})$ by precipitation in isopropanol and dried in vacuum until constant weight. Its spectrum shows similar signals and shifts that the previously described copolymers.

\section{Quaternization of synthesized block copolymers. Preparation of PS-b-PQMTA cationic copolymers.}

The synthetic methodology for the quaternization of block copolymers was as follows. To a solution of block copolymer in anhydrous DMF was added a large excess of butyl iodide (ratio copolymer/butyl iodide $\approx 1: 5$ ). The mixture was stirred at $80{ }^{\circ} \mathrm{C}$ for one week to ensure the complete reaction. The solution was poured into $n$-hexane and the copolymers isolated as brown oils. After that, the quaternized copolymers were obtained as brownish solids after purification by dialysis against distilled water to remove the residual products and finally freeze-drying. ${ }^{1} \mathrm{H}-\mathrm{NMR}$ of $\mathrm{PS}_{54}-b-\mathrm{PQMTA}_{36}\left(300 \mathrm{MHz} \mathrm{DMSO}-\mathrm{d}_{6}\right), \delta$ (ppm): 10.18 (s, $1 \mathrm{H}, \mathrm{CH}$ thiazolium), 9.22 (bs, $1 \mathrm{H}, \mathrm{CH}$ triazolium), 7.02-6.43 (m, $5 \mathrm{H}, \mathrm{H}_{\mathrm{Ar}} \mathrm{PS}$ ), 5.80-4.50 (m, $6 \mathrm{H}, \mathrm{OCH}_{2},{ }^{+} \mathrm{NCH}_{2}$ triazolium, ${ }^{+} \mathrm{NCH}_{2}$ thiazolium), 4.00-3.10 (m, $4 \mathrm{H}, \mathrm{NCH}_{2}$, $\left.\mathrm{CH}_{2}\right), 2.40-1.00\left(\mathrm{~m}, 13 \mathrm{H}, 6 \mathrm{CH}_{2}, \mathrm{CH}\right), 1.00-0.50\left(\mathrm{~m}, 9 \mathrm{H}, 3 \mathrm{CH}_{3}\right)$. 


\section{Evaluation of antimicrobial activity in solution}

Antimicrobial activities of the copolymers were evaluated by determining their minimum inhibitory concentrations (MIC) against the bacterial strains $S$. aureus and $P$. aeruginosa and the fungal strain $C$. parapsilosis by standard broth microdilution method [24]. Each copolymer was first dissolved in DMSO and then diluted with sterile Mueller-Hinton (MH) broth to obtain a final concentration of $1 \mathrm{mg} / \mathrm{mL}$ (the maximum final DMSO content was maintained below $6 \%$, the maximum allowed concentration for not being toxic for bacteria).[25, 26] Bacterial and fungal strains were cultured in 5\% sheep blood Columbia agar plates for $24 \mathrm{~h}$ in an incubator at $37^{\circ} \mathrm{C}$, then dispersed and adjusted with saline solution to a turbidity equivalent to $0.5-1$ McFarland turbidity standard $\left(1-3 \times 10^{8}\right.$ $\mathrm{CFU} / \mathrm{mL}$ ). This suspension was further diluted (1:100) with Mueller-Hinton broth to yield the working solution $\left(10^{6} \mathrm{CFU} / \mathrm{mL}\right)$. As a general broth microdilution procedure, $100 \mu \mathrm{L}$ from each polymer solution were placed in a 96-well round-bottom microplate. From these ones, $50 \mu \mathrm{L}$ were transferred to the next well and half-diluted with $50 \mu \mathrm{L}$ of broth media. Then, subsequent 1:2 serial dilutions were made across the plate. Finally, $50 \mu \mathrm{L}$ of the corresponding microbial working solution were added to each well. A well without antimicrobial polymer, containing only the tested microorganism, was used as positive growth control. After incubation at $37^{\circ} \mathrm{C}$ during 24 or $48 \mathrm{~h}$ for bacteria and fungi, respectively, the MIC was visually estimated from the lowest concentration of copolymer at which the growth of microorganisms was inhibited.

\section{Evaluation of antimicrobial activity in films}

Films of $12 \mathrm{~mm}$ in diameter were performed by spin-coating on round glass slides from mixtures of block copolymers with commercial high-molecular weight polystyrene matrix, $\mathrm{PS}_{1950}$, in ratios of 10,30 and $50 \% \mathrm{w} / \mathrm{w}$ in a $7 \% \mathrm{w} / \mathrm{v}$ DMF solution. After the spin-coating, the samples were dried at room temperature and no special treatment was performed. Antimicrobial activities of the prepared films were estimated following the E2149-01 standard method from the American Society for Testing and Materials (ASTM) [27] with minor modifications. The microorganisms $S$. aureus, $P$. aeruginosa and $C$. parapsilosis were grown on $5 \%$ sheep blood Columbia agar plates, and then adjusted to a working bacterial suspension of $5 \times 10^{5} \mathrm{CFU} / \mathrm{mL}$ with PBS. Each film was placed in a sterile falcon tube and $10 \mathrm{~mL}$ of the tested inoculum were then added. As control experiments, tubes with commercial $\mathrm{PS}_{1950}$ film, blends with $\mathrm{PS}_{54}$ macroinitiator at $30 \%$ and $50 \% \mathrm{w} / \mathrm{w}$ and with only inoculum were also prepared. The samples were agitated at $120 \mathrm{rpm}$ during $24 \mathrm{~h}$ and the bacteria concentrations at time 0 and after $24 \mathrm{~h}$ were calculated by plate count method over $5 \%$ sheep blood Columbia agar plates. The measurements were made at least in triplicate. 


\section{RESULTS AND DISCUSSION}

\section{Antimicrobial amphiphilic block copolymers synthesis and characterization}

The synthesis of these new antimicrobial copolymers was performed by combination of ATRP and copper-catalyzed azide-alkyne cicloaddition (CuAAC) click reaction. Two different approaches were used (see Scheme 1): (A) MTA monomer and copolymer are simultaneously synthetized by one-step 'click chemistry'/ATRP and (B) preformed MTA monomer is copolymerized by ATRP from PS macroinitiator.

A

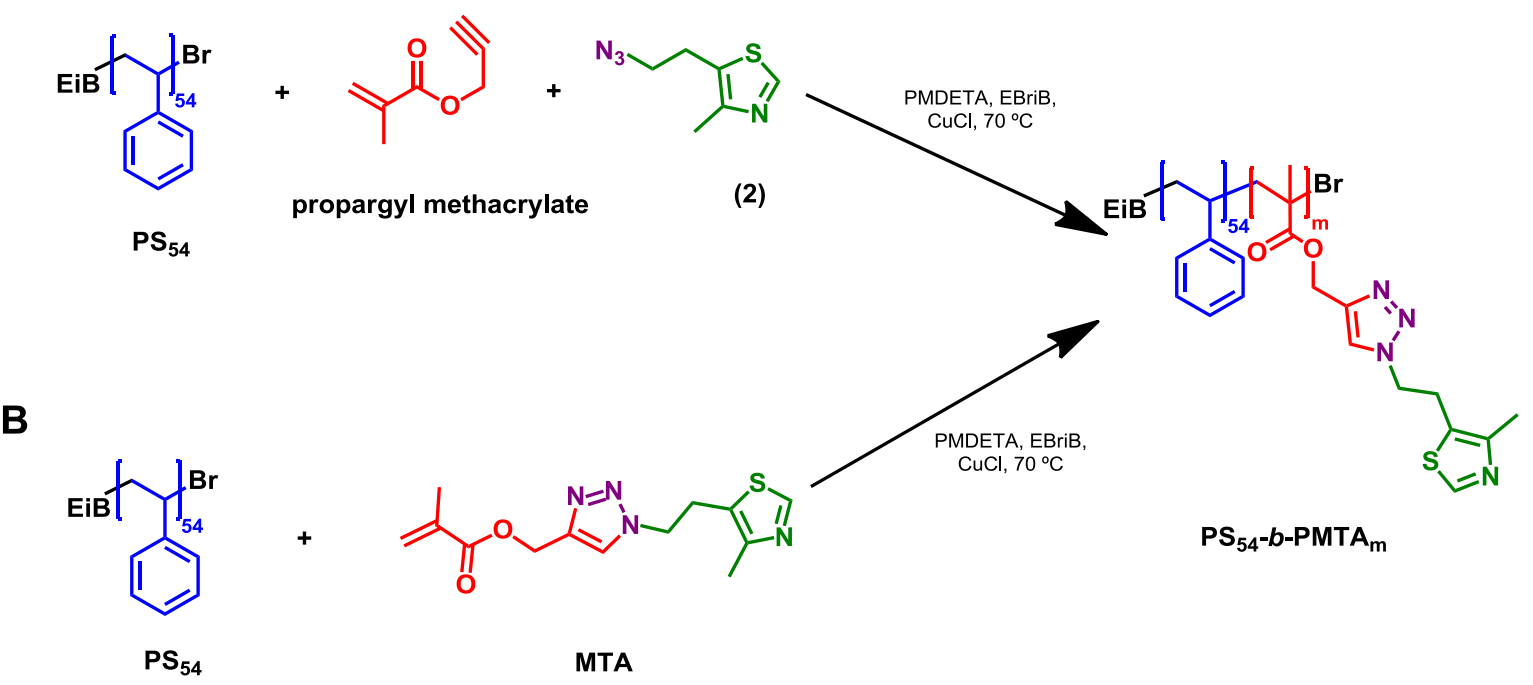

Scheme 1. Schematic representation of antimicrobial block copolymer synthesis by combination of ATRP and CUAAC click reaction.

In the first approach (route A), MTA monomer and copolymer are simultaneously synthesized by one-step click reaction/ATRP to obtain PS-b-PMTA block copolymers with different lengths of the hydrophilic PMTA block. Polystyrene block was previously synthetized by ATRP in order to use it as macroinitiator for subsequent formation of the block copolymer [28]. Specifically, it was synthesized using ethyl a-bromoisobutyrate (EBriB) as initiator, $\mathrm{CuBr}$ as catalyst and $N, N, N^{\prime}, N^{\prime \prime}, N^{\prime \prime}$-pentamethyldiethylenetriamine (PMDETA) as ligand. The reaction was carried out using a molar ratio of [S]:[EBriB]:[CuBr]:[PMDETA] = 60:1:1:1. The number average molecular weight, $M_{n}$, was $5660 \mathrm{~g} / \mathrm{mol}$ and polydispersity index, PDI, 1.21, as determined by GPC; therefore, PS macroinitiator presented 54 units: PS $_{54}$. In the subsequent one-pot ATRP/CuAAC reaction, the ratio of [macroinitiator]:[CuCl]:[PMDETA] was maintained at 1:1:4 for all 
reactions, while the ratio of [monomer]:[azide]:[macroinitiator] was 75:150:1; 150:300:1 and 300:600:1 to prepare the desired copolymers.

Figure 1 shows the NMR spectra obtained at different times in the copolymerization reaction of $\mathrm{PS}_{54}-b-\mathrm{PMTA}_{111}$. Signals corresponding to protons of thiazole ring and propargylic $\mathrm{CH}_{2}$ are indicated at zero time. Around $7.8 \mathrm{ppm}$ appears the $\mathrm{CH}$ signal corresponding to the new formed triazole ring, although it appears as very small signal due to the presence of DMF solvent $(8 \mathrm{ppm})$ in the sample. The disappearance of propargyl methylene signal at $4.6 \mathrm{ppm}$ concomitant with the appearance of a new signal at $5.2 \mathrm{ppm}$ attributed to the methylene of the thiazole ring indicate that 'click' reaction is instantaneously completed at the beginning of the reaction. In a previous work, these reactions were performed throughout poly(n-butyl methacrylate) macroinitiator and block copolymerization was as effective and successful as in this case with polystyrene [12]. Therefore, it seems that this change of macroinitiator does not modify the achievement of this combined reaction for MTA. The block copolymers were also characterized using gel permeation chromatography (GPC). The number-average molecular weights and the polydispersity indices obtained from both GPC and ${ }^{1} \mathrm{H}$-NMR are collected in Table 1. Narrow molecular weight distribution indicates that all copolymers were obtained in a controlled manner. However, molecular weights measured by these two techniques for each copolymer clearly differ from one another. It should be noted that GPC measurements have been performed against PMMA standards; thus, values obtained through this technique can be over or underestimated. Attending to this, molecular weights calculated through ${ }^{1} \mathrm{H}-\mathrm{NMR}$ were considered for the following experiments.

Under similar conditions, preformed MTA monomer is polymerized by ATRP from PS macroinitiator using a ratio [monomer]:[azide]:[macroinitiator]:[CuCl]:[PMDETA] of 150:300:1:1:4 (route B). ${ }^{1} \mathrm{H}-\mathrm{NMR}$ spectra at different times in the copolymerization reaction (see Figure $\mathrm{S} 2$ ) show that during the course of the reaction, the intensity of MTA vinyl signals at ca. 6.0 and 5.5 ppm decreases and signals for $\mathrm{O}-\mathrm{CH}_{2}$ and $\mathrm{N}-\mathrm{CH}_{2}$ at ca. $5.0 \mathrm{ppm}$ and $4.5 \mathrm{ppm}$ respectively, are shifted indicating that polymerization occurs. As can be observed (see Table 1), the final product, $\mathrm{PS}_{54}-b$-PMTA $A_{37}$, is quite similar to that obtained by the route $\mathrm{A}, \mathrm{PS}_{54}-b$-PMTA $\mathrm{A}_{36}$. For this reason, the following experiments were carried out exclusively with the copolymers prepared by route $A$. 


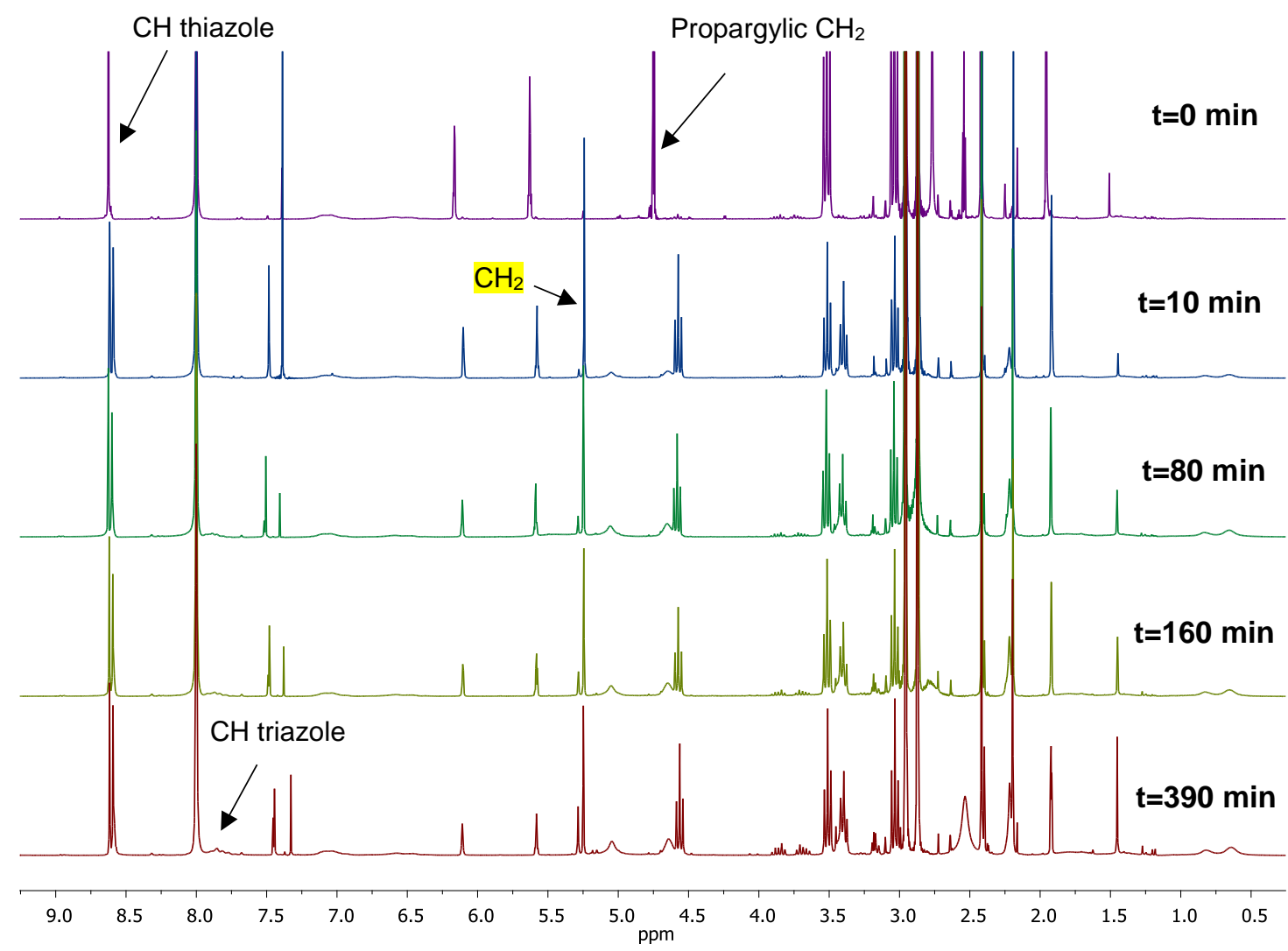

Figure 1. ${ }^{1} \mathrm{H}-\mathrm{NMR}$ spectra in $\mathrm{CDCl}_{3}$ at different reaction times for the synthesis of $\mathrm{PS}_{54}-\mathrm{b}$ PMTA $_{111}$.

Table 1. Number average molecular weight, $M_{n}$, obtained by GPC and calculated by ${ }^{1} \mathrm{H}-$ NMR; and polydispersity index, PDI, of copolymers PS $_{54}-b-P_{M T A}$.

\begin{tabular}{|c|c|c|c|c|}
\hline Copolymer & $\mathbf{M}_{\mathbf{n}}{ }^{\text {NMR }}(\mathbf{g} / \mathbf{m o l})$ & $\mathbf{M}_{\mathbf{n}}{ }^{\text {GPC }}(\mathbf{g} / \mathbf{m o l})$ & [PS]:[MTA] & PDI \\
\hline $\mathrm{PS}_{54}-b-\mathrm{PMTA}_{22}{ }^{\mathrm{a}}$ & 12080 & 22850 & $1: 75$ & 1.41 \\
$\mathrm{PS}_{54}-b-\mathrm{PMTA}_{36}{ }^{\mathrm{a}}$ & 16170 & 23300 & $1: 150$ & 1.16 \\
$\mathrm{PS}_{54}-b-\mathrm{PMTA}_{111}{ }^{\mathrm{a}}$ & 38070 & 35750 & $1: 300$ & 1.32 \\
$\mathrm{PS}_{54}-b-\mathrm{PMTA}_{37}{ }^{\mathrm{b}}$ & 16460 & 21200 & $1: 150$ & 1.13 \\
\hline
\end{tabular}

a) Copolymers obtained from route $A$.

b) Copolymer obtained from route $B$.

In addition, FTIR spectra have been recorded for these copolymers (see Figure S1). In the spectra is easily observed the variation of relative intensity between the band corresponding to PS $\left(699 \mathrm{~cm}^{-1}\right)$ and the one corresponding to PMTA carbonyl groups $\left(1740 \mathrm{~cm}^{-1}\right)$, which increases with the content of PMTA. 
As highlighted above, the vast majority of bacterial walls are negatively charged, mostly due to the presence of phosphatidylethanolamine. Accordingly, many antimicrobial polymers studied possess cationic moieties in order to increase their activity against pathogens $[5,6]$. In the present case, the block copolymer quaternization of thiazole and triazole groups ensures the presence of permanent positive charges at physiological conditions. The selection of the alkylating agent is crucial because the length of the alkyl agent determines the hydrophobic/hydrophilic balance and thus the antimicrobial activity.[6] In general, more hydrophobic chains interact better with the bacterial membrane, improving the bactericidal action; however, longer lengths significantly reduce the polymer solubility and increase polymer toxicity. Therefore, a balance is required to obtain an optimal structure. Previous investigations showed that the butyl quaternized PMTA homopolymers present a highly selective toxicity against microorganisms, because they are non-hemolytic exhibiting potent antimicrobial activity [22]. Hence, in this work the quaternization reactions were carried out with 1 -iodobutane in DMF at $80{ }^{\circ} \mathrm{C}$ using a great excess of alkylation agent with respect to the amount of nitrogen groups present in the copolymer. The resulting polymers incorporated 1,3-thiazolium and 1,2,3-triazolium groups. Full quaternization was achieved after one week as confirmed by ${ }^{1} \mathrm{H}-\mathrm{NMR}$ spectroscopy (Figure 2).

Quaternization percentages were calculated comparing ${ }^{1} \mathrm{H}-\mathrm{NMR}$ signal integrals of the corresponding protons of the thiazole and triazole rings before the reaction and once they were quaternized. All the modifications were achieved quantitatively. The two peaks assigned to the aromatic protons of the 1,2,3-thiazole and 1,3-triazole rings show different chemical shifts in the quaternized analogues. Initially, they appear at $8.57 \mathrm{ppm}$ and 7.82 ppm, respectively, then disappear and two new signals appear at higher $\delta$ shifts, 10.2 ppm for thiazolium and 9.2 ppm for triazolium rings as the reaction is elapsed (Figure 2). Total absence of triazole and thiazole protons in quaternized copolymer indicates that every nitrogen atom is quaternized. Similar spectra are obtained for each block copolymer. 


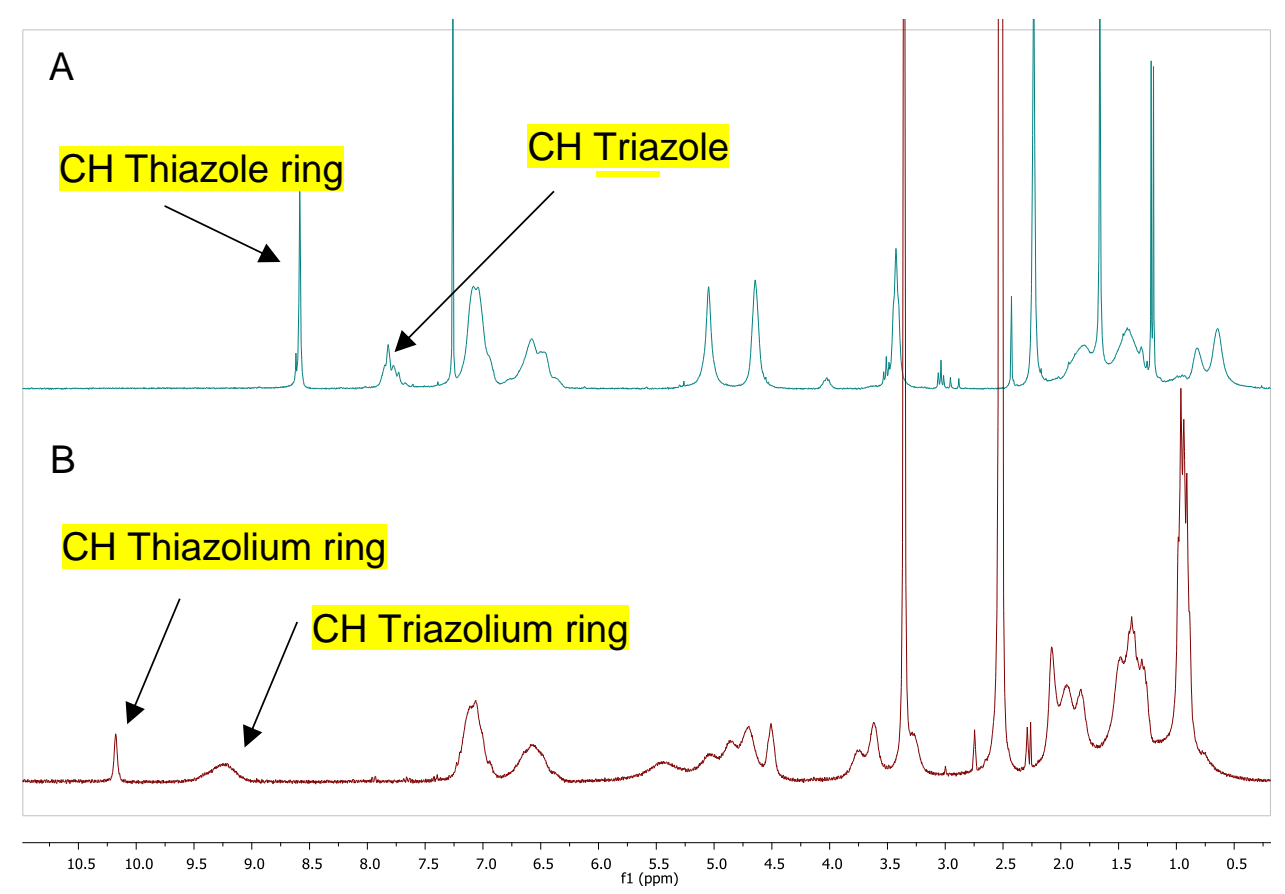

Figure 2. ${ }^{1} \mathrm{H}-\mathrm{NMR}$ spectra of $\mathrm{PS}_{54}-\mathrm{b}-\mathrm{PMTA}_{36}:(\mathrm{A})$ in $\mathrm{CDCl}_{3}$ before quaternization and $(\mathrm{B})$ quaternized polymer in DMSO- $\mathrm{d}_{6}$.

\section{Antimicrobial activity study}

Antimicrobial activity study of the quaternized copolymers in solution was carried out following the protocol M07-A9 described by the Clinical and Laboratory Standards Institute for the minimal inhibitory concentration (MIC) determination, which is the lowest concentration of an antimicrobial agent inhibiting the visible growth of a microorganism after overnight incubation. Three microbial strains were studied: $S$. aureus gram-positive bacterium, $P$. aeruginosa gram-negative bacterium and $C$. parapsilosis fungus. Results of this study are shown in Table 2.

From MIC values, the antimicrobial activity seems to increase as cationic segment length (PQMTA) augments, being more effective against gram-positive $S$. aureus bacteria. These facts are expected due to the higher number of active groups that interact with the cell wall and, thus, easily destroying it. Besides, the better activity found against gram positive bacteria is because those possess only one membrane; therefore, are more susceptible to be killed than gram negative bacteria, which have a double membrane. 
Table 2. Minimal inhibitory concentration (MIC) for each microorganism studied.

\begin{tabular}{|c|c|c|c|}
\cline { 2 - 4 } \multicolumn{1}{c|}{} & S. aureus & P. aeruginosa & C. parapsilosis \\
\hline Block copolymer & MIC $(\mu \mathrm{g} / \mathrm{mL})$ & MIC $(\mu \mathrm{g} / \mathrm{mL})$ & MIC $(\mu \mathrm{g} / \mathrm{mL})$ \\
\hline $\mathrm{PS}_{54}-b-\mathrm{PQMTA}_{22}$ & 125 & $>500$ & 125 \\
\hline $\mathrm{PS}_{54}-b-\mathrm{PQMTA}$ & & 500 & 500 \\
\hline $\mathrm{PS}_{54}-b-\mathrm{PQMTA}$ & 125 & 500 & 125 \\
\hline
\end{tabular}

However, the MIC values are relatively high even against gram-positive $S$. aureus when comparing with other copolymer systems containing the monomeric unit QMTA with triazolium and thiazolium moieties.[12, 23] This could be due to a self-assembly effect as a result of the relatively reduced solubility of these copolymers in water. Taking into consideration these weak results found in solution, we prepared films from these copolymers expecting a different behavior at the surfaces. Films of binary blends with commercial $\mathrm{PS}_{1950}$ and the different block copolymers in ratios of 10,30 and $50 \% \mathrm{w} / \mathrm{w}$ were made by spin-coating from $7 \% \mathrm{w} / \mathrm{v}$ DMF solutions. The antimicrobial activity of these films was also studied against the same microorganisms than in solution. The shake-flask method was employed to assess the antimicrobial ability of the prepared films by estimating the cell killing percentage after a fixed contact time of $24 \mathrm{~h}$. The reduction is expressed with respect to the control experiments. Several controls have been tested. For example, commercial PS has been compared with its mixtures with $\mathrm{PS}_{54}$ macroinitiator and the bacterial reduction has been null in both cases, meaning that the second block of PQMTA is the responsible of the antimicrobial activity and discarding any activity from neither the matrix nor the first PS block. The obtained results are summarized in Table 3. Typically, an antimicrobial surface can be considered effective when the percentage reduction of the microbial contamination is equal to or higher than $99.9 \%$, compared to not treated surface or control surfaces. As can be easily observed the behavior is similar to that observed in solution. The surfaces are more effective against gram-positive $S$. aureus bacteria than against gram-negative $P$. aeruginosa bacteria and than against $C$. parapsilosis fungi. However, a minimum copolymer concentration and also a minimum QMTA block length is needed to be effective. The block copolymer with only 22 units of QMTA has not enough quaternized units to be effective, even with ratio of $50 \%$ in the blend, although exhibits a certain activity against $C$. parapsilosis. In contrast, both $\mathrm{PS}_{54}-b$ $\mathrm{PQMTA}_{36}$ and $\mathrm{PS}_{54}-b-\mathrm{PQMTA} \mathrm{A}_{111}$ are efficient at composition higher than $10 \%$. Also, a 
general trend is observed, bacteria reduction increases with polymer percentage in the blend as expected.

Table 3. Bacteria elimination effectiveness for each system studied.

\begin{tabular}{|c|c|c|c|c|}
\hline & Blends & S. aureus & P. aeruginosa & C. parapsilosis \\
\hline Block copolymer & $\begin{array}{c}\mathrm{PS}_{1950} / \\
\mathrm{PS}_{54}-b-\mathrm{PQMTA} \mathrm{A}_{\mathrm{m}}\end{array}$ & \multicolumn{3}{|c|}{$\begin{array}{c}\text { Cell killing } \\
(\%)\end{array}$} \\
\hline \multirow{3}{*}{$\mathrm{PS}_{54}-b-\mathrm{PQMTA} \mathrm{A}_{22}$} & $90 / 10$ & 40 & 80 & 80 \\
\hline & $70 / 30$ & 60 & 85 & 75 \\
\hline & $50 / 50$ & 80 & 60 & 95 \\
\hline \multirow{3}{*}{$\mathrm{PS}_{54-b-\mathrm{PQMTA}} \mathrm{A}_{36}$} & $90 / 10$ & 80 & 80 & 95 \\
\hline & $70 / 30$ & 99.998 & 90 & 80 \\
\hline & $50 / 50$ & 99.998 & 98 & 50 \\
\hline \multirow{3}{*}{$\mathrm{PS}_{54}-b-\mathrm{PQMTA} \mathrm{A}_{111}$} & $90 / 10$ & 88 & 85 & 95 \\
\hline & $70 / 30$ & 99.9 & 95 & 95 \\
\hline & $50 / 50$ & 99.96 & 99.97 & 90 \\
\hline
\end{tabular}

In a previous study, block copolymers with PQMTA cationic block but with poly(butyl methacrylate) as hydrophobic block were used as surfactants in the emulsion polymerization of butyl methacrylate [12]. In that work, the films obtained with $3 \% \mathrm{w} / \mathrm{w}$ of block copolymer were not able to have a good bactericide effect due to the short length of QMTA active segment and the low amount of block copolymer present at the surface. In the current case, the lengths are quite similar but the amount of block copolymers in the coating is much higher, $10 \%, 30 \%$ and $50 \%$, which also seems to be a crucial factor. Thus, higher amounts allow an abundantly covering of the surface providing it with strong antimicrobial character. Most of these films are bactericide systems against $S$. aureus bacteria with log-reduction higher than 3 , that is, $99.9 \%$ of microorganism eliminated [29]. However, this strong effect is depressed against $P$. aeruginosa bacteria or $C$. parapsilosis fungi, which are more difficult to eliminate with polycations [6].

As an example, Figure 3 shows the FE-SEM images of the film surface obtained from the blend $\mathrm{PS}_{1950} / \mathrm{PS}_{54}-b-\mathrm{PQMTA} \mathrm{A}_{36}: 70 / 30$ after incubation with $S$. aureus bacteria during $24 \mathrm{~h}$. It is clearly observed a significant reduction in the bacterial population in comparison with the control film, made from PS matrix in the absence of any antimicrobial copolymer. This 
seems to indicate that once the bacteria are killed, detach from the surface. Nevertheless, at the bottom of the Figure $3 \mathrm{~b}$ it is appreciated regions of aggregates (red arrows) probably formed from intracellular material of death bacteria.
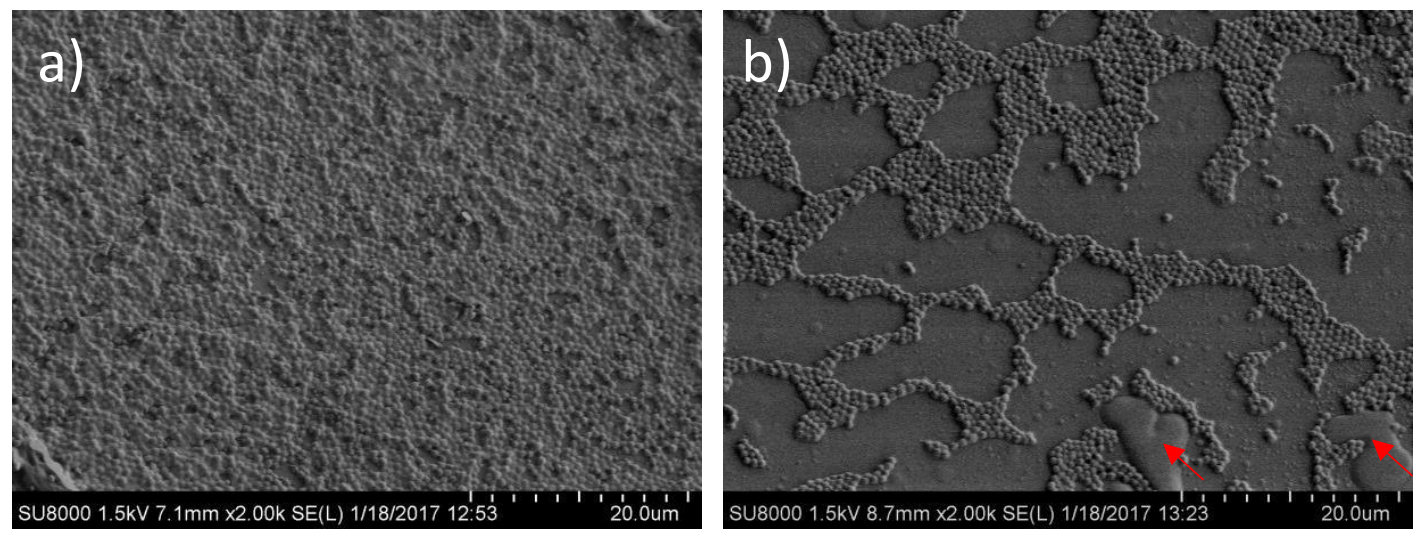

Figure 3. FE-SEM images of $S$. aureus on PS films a) in the absence and $b$ ) in the presence of the antimicrobial copolymer $\mathrm{PS}_{54}-b-\mathrm{PQMTA}_{36} \quad\left(\mathrm{PS}_{1950} / \mathrm{PS}_{54-}-b\right.$ PQMTA $\left._{36}: 70 / 30\right)$ after $24 \mathrm{~h}$ of contact.

\section{Conclusions}

In summary, novel amphiphilic block copolymers with different molecular weights and good polydispersity indexes have been synthetized by simultaneous copper catalyzed atom transfer radical polymerization and copper(I)-catalyzed azide-alkyne cycloaddition (CuAAc). The comparison with a block copolymer synthesized using the preformed MTA monomer and similar molecular characteristics, indicates that this methodology is straightforward avoiding the monomer synthesis and purification processes. These copolymers contain a hydrophobic block, PS, and a hydrophilic block, PMTA, which carries one thiazole group and another triazole ring. Both rings have been quaternized with 1-iodobutane in order to enhance their antimicrobial activity. Antimicrobial assays were carried out against gram-positive $S$. aureus and gram-negative $S$. aeruginosa bacteria, and $C$. parapsilosis fungi. In solution, $\mathrm{PS}_{54}-b-\mathrm{PQMTA}_{111}$ shows the highest antimicrobial activity due to its larger number of quaternized MTA units. All block copolymers have shown more activity against $S$. aureus bacteria, as expected, given that gram-positive bacteria have only one membrane; therefore, they are more easily destroyed with this type of cationic polymers. Films formed from blends of this copolymers with commercial polystyrene demonstrate that are also able to eliminate microorganisms. However, for an adequate antimicrobial performance it is needed not only a certain active 
block length in the copolymer but also enough block copolymer amount must be present in the blend to be bactericide.

\section{Acknowledgments}

This work was supported financially by the MINECO (Projects MAT2013-47902-C2-1-R and MAT2016-78437-R).

\section{References}

[1] Antiobiotic Resistance Threats in the U.S.: U.S. Department of Health and Human Services; 2013.

[2] O'Neill J. Antimicrobial Resistance: Tackling a crisis for the health and wealth of nations. The Review on Antimicrobial Resistance 2014.

[3] Rawlinson K. Outbreak of drug-resistant infection could kill 80,000 in UK, report warns. The Guardian; 2015.

[4] Alamri A, El-Newehy M, Al-Deyab S. Biocidal polymers: synthesis and antimicrobial properties of benzaldehyde derivatives immobilized onto amine-terminated polyacrylonitrile. Chemistry Central Journal. 2012;6(1):111.

[5] Muñoz-Bonilla A, Fernández-García M. The roadmap of antimicrobial polymeric materials in macromolecular nanotechnology. Eur Polym J. 2015;65:46-62.

[6] Muñoz-Bonilla A, Fernández-García M. Polymeric materials with antimicrobial activity. Prog Polym Sci. 2012;37(2):281-339.

[7] Jaeger W, Bohrisch J, Laschewsky A. Synthetic polymers with quaternary nitrogen atoms--Synthesis and structure of the most used type of cationic polyelectrolytes. Prog Polym Sci. 2010;35(5):511-577.

[8] Matyjaszewski K, Muller AHE. 50 years of living polymerization. Prog Polym Sci. 2006;31(12):1039-1040.

[9] Braunecker WA, Matyjaszewski K. Controlled/living radical polymerization: Features, developments, and perspectives. Prog Polym Sci. 2007;32(1):93-146.

[10] Wang J-S, Matyjaszewski K. Controlled/"Living" Radical Polymerization. Halogen Atom Transfer Radical Polymerization Promoted by a $\mathrm{Cu}(\mathrm{I}) / \mathrm{Cu}(\mathrm{II})$ Redox Process. Macromolecules. 1995;28(23):7901-7910.

[11] Koromilas ND, Lainioti GC, Vasilopoulos G, Vantarakis A, Kallitsis JK. Synthesis of antimicrobial block copolymers bearing immobilized bacteriostatic groups. Polym Chem. 2016;7(21):3562-3575.

[12] Alvarez-Paino $M$, Juan-Rodríguez R, Cuervo-Rodríguez R, Tejero R, López D, López-Fabal F, et al. Antimicrobial films obtained from latex particles functionalized with quaternized block copolymers. Colloids Surf B Biointerfaces. 2016;140:94-103.

[13] Ohno K, Izu Y, Tsujii Y, Fukuda T, Kitano H. Some aspects of nitroxide-mediated living radical polymerization of $\mathrm{N}$-(p-vinylbenzyl)phthalimide. Eur Polym J. 2004;40(1):8188.

[14] Ignatova M, Voccia S, Gilbert B, Markova N, Mercuri PS, Galleni M, et al. Synthesis of Copolymer Brushes Endowed with Adhesion to Stainless Steel Surfaces and Antibacterial Properties by Controlled Nitroxide-Mediated Radical Polymerization. Langmuir. 2004;20(24):10718-10726.

[15] Roy D, Knapp JS, Guthrie JT, Perrier S. Antibacterial Cellulose Fiber via RAFT Surface Graft Polymerization. Biomacromolecules. 2007;9(1):91-99.

[16] Ghosh A, Yusa S-i, Matsuoka H, Saruwatari Y. Chain Length Dependence of NonSurface Activity and Micellization Behavior of Cationic Amphiphilic Diblock Copolymers. Langmuir. 2014;30(12):3319-3328.

[17] Obadia MM, Drockenmuller E. Poly(1,2,3-triazolium)s: a new class of functional polymer electrolytes. Chem Commun. 2016;52(12):2433-2450. 
[18] Hawker CJ, Wooley KL. The Convergence of Synthetic Organic and Polymer Chemistries. Science. 2005;309(5738):1200-1205.

[19] Adzima BJ, Taylor SC, He H, Luebke DR, Matyjaszewski K, Nulwala HB. Vinyltriazolium monomers: Versatile and new class of radically polymerizable ionic monomers. J Polym Sci, Part A: Polym Chem. 2014;52(3):417-423.

[20] Huisgen R, Szeimies G, Möbius L. 1.3-Dipolare Cycloadditionen, XXXII. Kinetik der Additionen organischer Azide an CC-Mehrfachbindungen. Chem Ber. 1967;100(8):24942507.

[21] Tejero R, López D, López-Fabal F, Gómez-Garcés JL, Fernández-García M. High Efficiency Antimicrobial Thiazolium and Triazolium Side-Chain Polymethacrylates Obtained by Controlled Alkylation of the Corresponding Azole Derivatives. Biomacromolecules. 2015;16(6):1844-1854.

[22] Tejero R, Lopez D, Lopez-Fabal F, Gomez-Garces JL, Fernandez-Garcia M. Antimicrobial Polymethacrylates based on Quaternized 1,3-Thiazole and 1,2,3-Triazole Side-Chain Groups. Polym Chem. 2015;6(18):3449-3459.

[23] Tejero R, Gutiérrez B, López D, López-Fabal F, Gómez-Garcés JL, FernándezGarcía M. Copolymers of acrylonitrile with quaternizable thiazole and triazole side-chain methacrylates as potent antimicrobial and hemocompatible systems. Acta Biomater. 2015;25:86-96.

[24] CLSI. Methods for Dilution Antimicrobial Susceptibility Tests for Bacteria That Grow Aerobically; Approved Standard-Ninth Edition: CLSI document M07-A9. Wayne, PA: Clinical and Laboratory Standards Institute; 2012.

[25] Hansen LK, Brown M, Johnson D, Palme DF, Love C, Darouiche R. In Vivo Model of Human Pathogen Infection and Demonstration of Efficacy by an Antimicrobial Pouch for Pacing Devices. Pace-Pacing and Clinical Electrophysiology. 2009;32(7):898-907.

[26] Álvarez-Paino M, Muñoz-Bonilla A, López-Fabal F, Gómez-Garcés JL, Heuts JPA, Fernández-García M. Effect of glycounits on the antimicrobial properties and toxicity behavior of polymers based on quaternized DMAEMA. Biomacromolecules. 2015;16(1):295-303.

[27] ASTM E2149-01, Standard Test Method for Determining the Antimicrobial Activity of Immobilized Antimicrobial Agents Under Dynamic Contact Conditions (Withdrawn 2010). ASTM International, West Conshohocken, PA, 2001, www.astm.org.

[28] Munoz-Bonilla A, Ali SI, del Campo A, Fernandez-Garcia M, van Herk AM, Heuts JPA. Block Copolymer Surfactants in Emulsion Polymerization: Influence of the Miscibility of the Hydrophobic Block on Kinetics, Particle Morphology, and Film Formation. Macromolecules. 2011;44(11):4282-4290.

[29] Pankey GA, Sabath LD. Clinical Relevance of Bacteriostatic versus Bactericidal Mechanisms of Action in the Treatment of Gram-Positive Bacterial Infections. Clin Infect Dis. 2004;38(6):864-870. 